\title{
DOI: https://doi.org/10.24297/jac.v16i0.8499
}

\section{Synthesis and DFT Study of Newly Schiff Base and Fused Heterocyclic Compounds as Antibacterial Agent}

\author{
Sameh A. Rizk1*, Ismail M. Awheda2, Fathy A. Smida2 \\ 1Department of Chemistry, Faculty of Science, University of Ain Shams, Cairo, Egypt \\ 2Department of Chemistry, Faculty of Art and Science, University of Mergeb, Triboli, Lybia \\ *Samehrizk@sci.asu.edu.eg,
}

\begin{abstract}
:
Treatment of 2,3-di-(4-chlorophenyl) oxirane-2,3-dicarbonitriles(1) with nitrogen nucleophiles, e.g. N2H4, $\mathrm{NH} 2 \mathrm{OH}$ afforded pyrazole 2, 1.2oxazole 3 derivatives respectively The 3-amino pyrazole-4-one derivatives 2 can be used as a key starting materials to synthesize some important Schiff base 4 and fused heterocyclic compounds e.g. Imidazolo-[4,5-c]pyrazole 5, Pyrazolo[3,4-e]1,2,4-triazine 6, pyrazol[1,2-a] 1,3,5-triazine 7, 8 and 9. The electromeric effect of the halogen atom in the aryl moieties can be controlled upon the rate of reaction and the yield of the product. The structures of synthesized new compounds were characterized by spectral data and screened for their antimicrobial activities against various bacteria and fungi strains. The heterocyclic compounds 7, 8 and 9 that contained bridgehead nitrogen gave an excellent result.
\end{abstract}

Keywords: Oxirane, Pyrazole, Isooxazole, Schiff Base, Imidazole, Triazine.

\section{Introduction}

2,3-Diaryloxirane-2,3-dicarbonitriles were well-known as important synthetic intermediates [1]. The reported synthetic method for 2,3-diaryloxirane-2,3-dicarbonitriles to afford the substituted pyrazole and isoxazole moieties should be discussed [2,3]. An important class of compounds in the field of agricultural and medicinal chemistry because of their broad-spectrum biological activities [4,5], cancer therapy such as pyrazoles [6]. Successful as antifungal agents and when fused imidazole derivatives [7-9] were combined with antibacterial agents (vancomycin, ciprofloxacin) that observed antagonistic activity results from the competitive binding of the medicine molecules into fungi cells receptors. Also, the imidazolo-oxazole derivatives have been tested for antimycobacterial activity via treatment of imidazole derivatives with oxirane and the presence of imidazolothiadiazole moieties that be considered as antibacterial agents. 3-phenylamino-(substituted phenyl) isoxazolines [10-12] were evaluated for their in vitro antifungal activity and on the proliferative response of human mononuclear peripheral blood cells to phytohemagglutinin A (PHA). Schiff bases have remarkable property of forming complexes and serve as excellent chelating ligands and have been used [13-20] as analytical reagents for the spectrophotometric determination of metal ions. It's reported [21-25] that the behavior of 2,3-diaryloxirane-2,3-dicarbonitriles towards different carbon and nitrogen nucleophiles.

\section{Results and Discussion}

\section{Chemistry}

The different kinds of electrophilic centre in the 2,3-Diaryloxirane-2,3-dicarbonitriles (1) can able to be allowed to react with simply bi-nucleophiles to afford the new heterocyclic compounds, they were depended upon the type of nucleophile. The stability of the Schiff bases 4 can be controlled upon the migration of the 
aryl groups in position 5 in pyrazole moiety, whenever the attacking nucleophiles approached. The reaction of 2,3-diaryl oxirane-2,3-dicarbonitriles (1) can be allowed to react with simply binucleophiles e.g. hydrazine derivatives and hydroxylamine (Scheme 1) to afford an important heterocyclic compounds pyrazole and isoxazole derivatives respectively. The reaction of the cyano oxirane 1 with hydrazine hydrate affords the pyrazole derivatives 2 . The yield of the products reflected the stability of the compounds 2 and how the aryl substituents have been saved theirs and occur intramolecular $1,2[\mathrm{H}]$ shift to afford the more stable products. But, the formation of the isoxazole derivatives 3 can be proved that the mechanism could be of the bonding rearrangement as outlined in figure of intermediate (Scheme 1).

Fig 1 outline the HOMO and LUMO optimization structure of the Schiff base 4

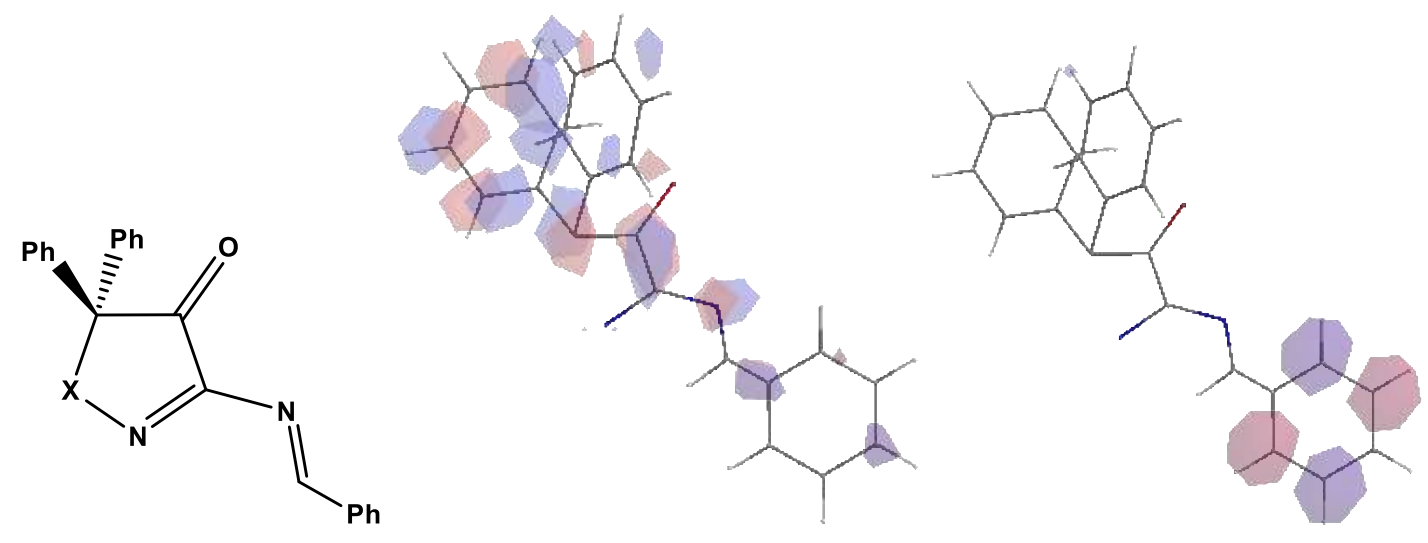

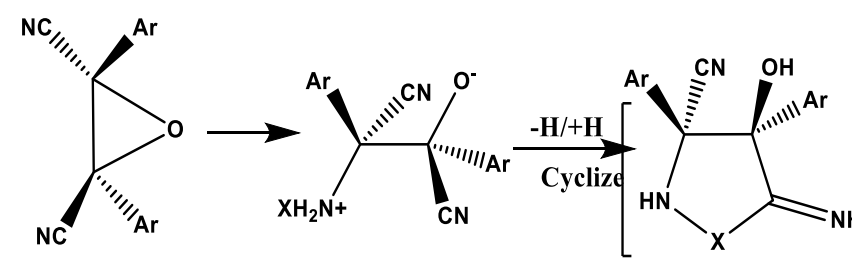

1

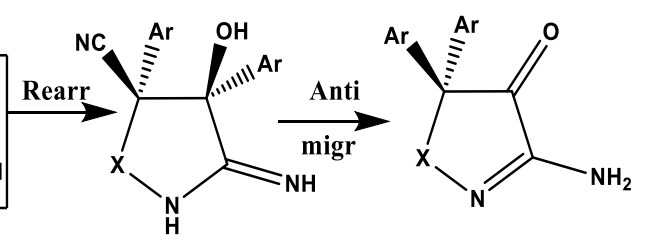

$2 \mathrm{X}=\mathrm{NH}$ 3, $\mathrm{X}=\mathbf{O}$

PhCHO

$\left.\mathrm{Ar}=(4-\mathrm{Cl}) \mathrm{C}_{6} \mathrm{H}_{4}\right)$

Scheme 1

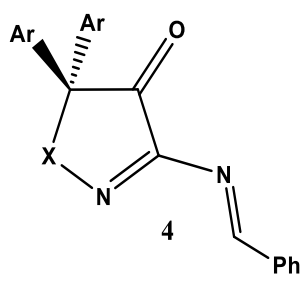




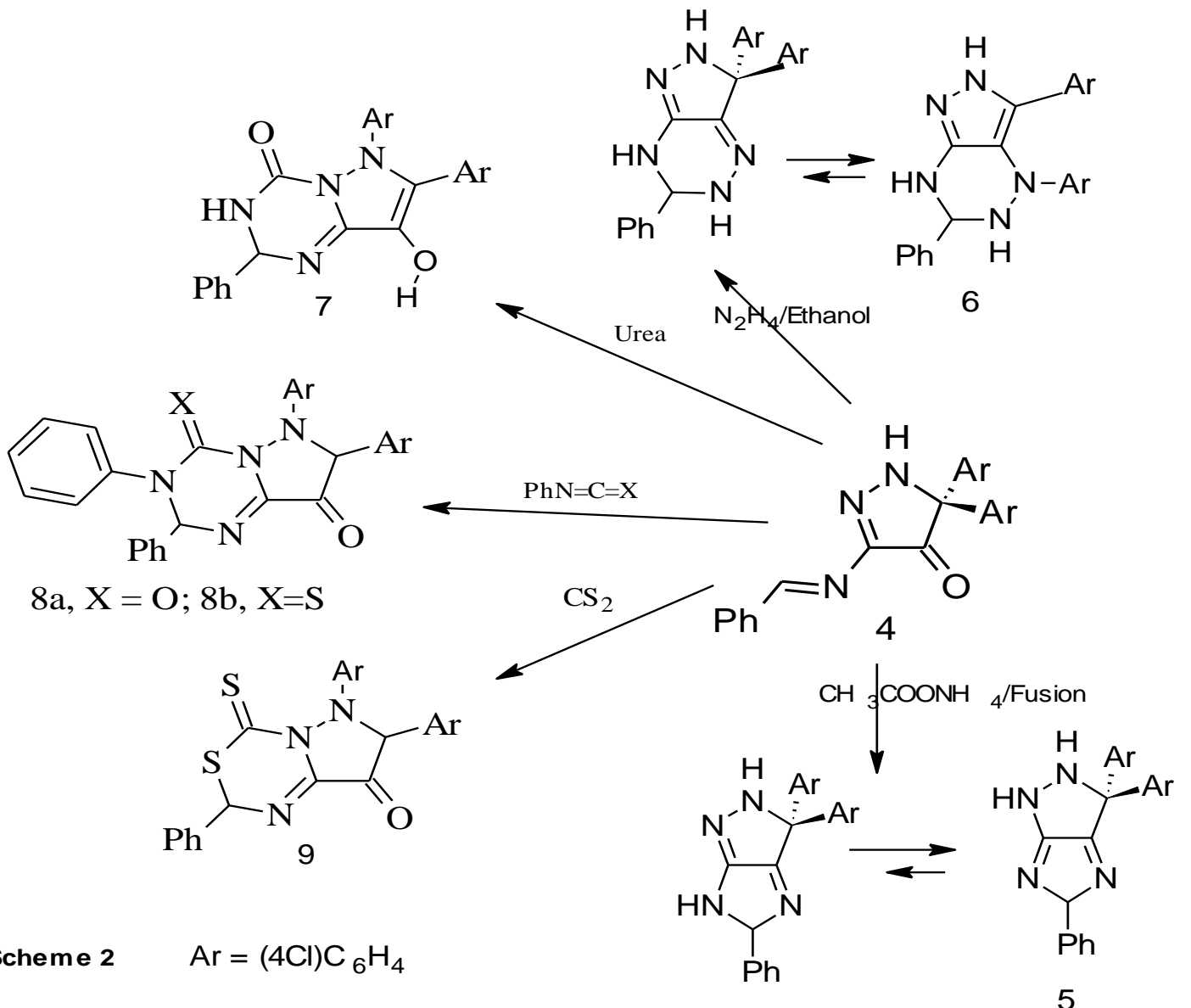

The

$\mathrm{Ar}=(4 \mathrm{Cl}) \mathrm{C}_{6} \mathrm{H}_{4}$

spectral analysis indicated the presence of carbonyl groups, and the absence of the cyano groups. The substituted aryl groups (electrometric effect of chlorine atom that presented in the aryl group) caused increase the migratory aptitude of aryl groups and deactivating the enamine group and enhanced the rate of reaction. The pyrazole derivatives 2 can be supported chemically when the pyrazole derivatives 2 were submitted to react with benzaldehyde in the presence of boiling ethanol afforded the Schiff base 4 . The presence of halogen atom in Schiff base can be affected upon their reactivity and increased the yield of products. Moreover, DFT study can be outlined the electron density sites of the Schiff base and helped the authors to explain the reaction course of the Schiff base 4 with different nucleophilic and electrophilic reagents. So, fusion of the arylidene 4 with ammonium acetate afford imidazolopyrazole 5 in high yield due to improvement the electronic effect of the chlorine atom. Refluxing the arylidene 4 with hydrazine hydrate in boiling ethanol afforded the pyrazolo[3,4-e] 1,2,4-triazine derivatives 6 (Scheme 2). The derivatives 5, and 6 were in good yield via spontaneous $[1,3] \mathrm{H}$ shift to afford the more thermodynamically stable (cisoid form) of the derivatives 5 and 6. 1,3-Hydrogen shift was energetically more favored to transfer than the aryl group that transfer to nitrogen. It's well-known that the electron-rich rings are good migrating group, so they can be enhancement the rate of reaction.

13C-NMR can be confirmed that the two aryl groups were in a different position and not on the same site, i.e. occur migration. Now, let's take a more detailed look when the Schiff base 4 could be allowed to react with urea in boiling ethanol afforded pyrazolotriazine 7. The elemental and spectral data are agreement with the structure of the isolated products 7. The simplified 1H-, 13C-NMR of the 4 aryl groups can have helped us to form the proposal mechanism to afford pyrazolotriazine derivatives 7. The reaction of the arylidene of pyrazolone 4 with carbon electrophiles, e.g. phenyl of both isocyanate, and isothiocyanate afforded 
pyrazolo[1,2-a]1,3,5-triazine $8 \mathrm{a}$, and $8 \mathrm{~b}$ respectively. The reaction was formed via the nucleophilic addition of $\mathrm{N} 2$ of the pyrazole, migration of aryl followed by the ring closure. The driving force to the migration of the aryl group was due to afford the more thermodynamic stable aromaticity and intramolecular hydrogen bond in addition to steric crowding support to the formation of the product $8 \mathrm{a}$ that confirmed by the $1 \mathrm{H}$ - and $13 \mathrm{C}$ NMR spectra inside of the product $8 \mathrm{~b}$. The pyrazolo[1,2-c]1,3,4-thiadiazine 9 can be isolated only via the reaction of the $\mathrm{N} 2$ of pyrazole as nucleophile with carbon disulfide as electrophile and ring migration followed by cyclization. The structure of product 9 can be confirmed by elemental and spectral date. Pyrazolo[1,2a]1,3,5-triazine and the corresponding heterocyclic analogs are valuable intermediates in organic synthesis [26] and exhibit a multitude of biological activities [27], widespread distributed in fruits, vegetables, spices, tea and soy-based foodstuff, and subject of great interest for their interesting pharmacological activities [28]. They have been recently one of the important biocides and versatile synthons for various chemical transformations and highly biologically active with a number of pharmacological and medicinal applications $[29,30]$.

\section{ii- Biological activity}

From the structure-activity relationship (SAR) between aryl vinyl amide and synthetic Schiff base, 4 can be indicated the bioisosteric of tyrosine kinase inhibition [31]. From (Table 1), antimicrobial activities of some synthetic compounds $2,3,4,5,6,7,8$ and 9 have stronger than the natural antibiotics. The authors could be explained the bridgehead nitrogen compounds $7,8 \mathrm{a}, 8 \mathrm{~b}$ and 9 that similar to three drugs used to treat erectile dysfunction (sildenafil, tadalafil, and vardenafil). There are a wide variety of phosphodiesterases throughout the body. These enzymes hydrolyze the cyclic phosphate esters of adenosine monophosphate (cAMP) and guanosine monophosphate (cGMP). Although the substrates for this family of enzymes are cAMP and cGMP, there are differences in the active sites. They have an important role in maintaining a desired lifestyle: treatment of erectile dysfunction caused by various medical conditions.

Table 1. Antibacterial activity of the synthesized compounds: Agar diffusion method.

\begin{tabular}{lllll} 
& \multicolumn{2}{l}{ Gram-Positive } & \multicolumn{2}{c}{ Gram-Negative } \\
\cline { 2 - 5 } Compound No. & $\begin{array}{l}\text { Staphylococcus } \\
\text { aureus }\end{array}$ & $\begin{array}{l}\text { Bacillus } \\
\text { cereus }\end{array}$ & $\begin{array}{l}\text { Serratia } \\
\text { marcesens }\end{array}$ & $\begin{array}{l}\text { Proteus } \\
\text { mirabilis }\end{array}$ \\
\hline 2 & ++ & ++ & + & ++ \\
3 & ++ & ++ & ++ & ++ \\
4 & ++ & ++ & ++ & ++ \\
5 & + & ++ & ++ & ++ \\
6 & ++ & + & + & + \\
7 & + & ++ & ++ & - \\
8 & ++ & ++ & ++ & + \\
9 & ++ & ++ & ++ & + \\
Chloramphenicol ${ }^{2}$ & +++ & +++ & +++ & +++ \\
Ampicillin ${ }^{2}$ & +++ & +++ & +++ & +++ \\
\hline
\end{tabular}

The width of the zone of inhibition indicates the potency of antibacterial activity; (-) no antibacterial activity $(0 \%-25 \%) ;(+)$ mild activity with the diameter of the zones equal to $0.5-0.8 \mathrm{~cm}$ (25dehydroascorbate $40 \%)$, 
$(++)$ moderate activity with the diameter of the zones equal to $1.1-1.2 \mathrm{~cm}(55 \%-65 \%) ;(+++)$ marked high activity with the diameter of the zones equal to $1.8-2.0 \mathrm{~cm}(85 \%-100 \%)$.

\section{Conclusion}

In the present work, the authors can be succeeded to the synthesis of a series of some important Schiff bases and novel fused heterocycle derivatives, that be expected to enhance the biological profile many folds than their parent nuclei. The electromeric effect of halogen can be controlled in the rate of reaction and enhances the yield of synthesized fused heterocycles. Migration of the aryl groups in derivatives of 5, 7, 8, and 9 can be confirmed by $1 \mathrm{H}$ - and 13C-NMR. The bioisoster of synthetic arylidene of Schiff base to arylvinylamide that expects to enhance the biological profile many folds than their parent nuclei. Enhancement of the mono- and bi-cyclic compounds contain hetero atom as antimicrobial prove that the process of degradation of microbe proceeds via enzymatic inhibition.

\section{Acknowledgment}

The author wishes to express his gratitude to the chemistry department of Ain- Shams, and El-Mergeb Universities for providing the research assistance for carrying out the pilot project.

\section{Experimental}

All melting points are uncorrected and were determined on a Stuart electric melting point apparatus. Elemental analyses were carried out at the Microanalytical Centre, National Research Centre, Cairo, Egypt. By Elementary Viro El Microanalysis IR spectra $(\mathrm{KBr})$ were recorded on infrared spectrometer FT-IR 400D using OMNIC program and are reported frequency of absorption in terms of $\mathrm{cm}-1$ and $1 \mathrm{H}-\mathrm{NMR}$ spectra recorded on a Bruker spectrophotometer at $400 \mathrm{MHz}$ using TMS as internal standard and with residual signals of the deuterated solvent $\delta=7.26 \mathrm{ppm}$ for $\mathrm{CDCl} 3$ and $\delta 2.51 \mathrm{ppm}$ for DMSO-d6. 13C-NMR spectra were recorded on the same spectrometer at $100 \mathrm{MHz}$ and referenced to solvent signals $\delta=77 \mathrm{ppm}$ for $\mathrm{CDCl} 3$ and $\delta 39.50 \mathrm{ppm}$ for DMSO-d6. DEPT 135 NMR spectroscopy were used where appropriate to aid the assignment of signals in the $1 \mathrm{H}$ and $13 \mathrm{C}-\mathrm{NMR}$ spectra. The mass spectra were recorded on Shimadzu GCMS-QP-1000 EX mass spectrometer at 70 e.v using the electron ionization technique. Homogeneity of all compounds synthesized was checked by TLC.

General Procedure for the preparation of the compounds 1 is described in the literature[1b].

The mixture of $\mathrm{K} 4[\mathrm{Fe}(\mathrm{CN}) 6](0.2 \mathrm{mmol})$ and aroyl chloride $(1 \mathrm{mmol})$ was heated at $160 \mathrm{oC}$ for $3 \mathrm{~h}$. Then the reaction mixture was cooled to room temperature, and triphenylphosphine $(0.5 \mathrm{mmol})$ and triethylamine $(0.02 \mathrm{mmol})$ in $10 \mathrm{~mL}$ of $\mathrm{CH} 2 \mathrm{Cl} 2$ were added. The resulting mixture was stirred at room temperature. After completion of the reaction, monitored by TLC, the resulting mixture was evaporated off the solvent, and the residue was subjected to column chromatography to give the pure product.

General Procedure for the preparation of the compounds 2

An equimolar mixture of compounds $1(2.26-3.14 \mathrm{~g} 0.01 \mathrm{~mol})$ and hydrazine hydrate $(0.01 \mathrm{~mol})$ in $50 \mathrm{~mL}$ boiling ethanol. The reaction mixture was refluxed for $6 \mathrm{~h}$. The solid that separated after cool was filtered off, washed by petroleum ether (b.p 40-60oC), dried and then, crystallized from the proper solvents. 3-Amino-5,5-bis(4chlorophenyl)-4-oxo-4,5-dihydropyrazole (2). Yield 74\%. m.p. 
238-240. IR(KBr) v 3390, 3255(NH), 3055(CHAr), 1706(CO). 1HNMR (DMSO): $\delta 7.45-7.7$ (m, 8H,ArH), singlet at $6.7,8.3$, and 13.2 a acidic $3 \mathrm{NH}$ protons which exchanged in D2O, 13C-NMR $\delta 113.6(2 \mathrm{C}), 122.1(2 \mathrm{CH})$, 128.0(2(H), 129.9(CH), 131.3(CH), 132.6(2CH), 135.6(CH), 139.6(CH), 141.5(C), $167.4(\mathrm{C}), 190.2(\mathrm{C})$ and Anal. Calc. for C15H11N3OCl2: C 56.42, H 3.44, N 13.16, Cl 21.94; found: C 56.47, H 3.39, N 13.12, Cl 21.88. MS:m/z $319[\mathrm{M}+],$.283.5 [M-Cl], 234[diarylmethine]+, 193 [3-amino- 5(4-chlorophenyl) pyrazole] +, 137.5, 70.

General Procedure for the preparation of the compounds 3

A mixture of $1(2.26-3.14 \mathrm{~g} ; 0.01 \mathrm{~mol})$ and hydroxyl amine hydrochloride $(1.03 \mathrm{~g} ; 0.015 \mathrm{~mol})$ in boiling pyridine $(50 \mathrm{~mL})$ and was heated under reflux for $6 \mathrm{~h}$. The reaction mixture was allowed to cool, pour into ice $/ \mathrm{HCl}$ and the product was filtered, dried, and were recrystallized from suitable solvent.

3-Amino-5,5-bis(4-chlorophenyl)-4-oxo-4,5-dihydro-1,2-oxazole (3). Yield 72\%. m.p. 238-240. IR(KBr) v 3336(NH), 3062 (CHAr), 1726(CO). 1HNMR (DMSO): $\delta 7.5-7.8(\mathrm{~m}, 8 \mathrm{H}, \mathrm{ArH})$, singlet at 8.1, 12.3 a acidic $2 \mathrm{NH}$ protons which exchanged in D2O, 13C-NMR $\delta 113.6(2 \mathrm{C}), 122.1(2 \mathrm{CH}), 128.0(2 \mathrm{CH}), 129.9(\mathrm{CH}), 131.3(\mathrm{CH})$, 132.6(2CH), 135.6(CH), 139.6(CH), 141.5(C), 167.4 (C), 190.2(C) and Anal. Calc. for C15H10N2O2Cl2: C 56.25, H 3.12, N 8.75, Cl 21.87; found: C 56.27, H 3.15, N 8.72, Cl 21.88. MS:m/z 320[M+.], 292 [M-CO], 284.5 [M-Cl], 251[diarylketone+.], 234, 140.

General Procedure for the preparation of the compounds 4

An equimolar mixture of compounds $2(2.4-3.3 \mathrm{~g} ; 0.01 \mathrm{~mol})$ and benzaldehyde $(0.01 \mathrm{~mol})$ in $50 \mathrm{~mL}$ boiling ethanol. The reaction mixture was refluxed for $4 \mathrm{~h}$. The solid that separated after cool was filtered off, dried and then, crystallized from the proper solvents.

3-(Benzylidenimino)-5,5-bis(4-chlorophenyl)-4-oxo-4,5-dihydro pyrazole (4). Yield 76\%. m.p.252-254. IR (KBr) v 3264(NH), 3058(CHAr), 1729 (CO). 1HNMR (DMSO): $\delta 6.2(\mathrm{~s}, 1 \mathrm{H}, \mathrm{CH}=)$, multiplet $7.12-7.89$ assigned for $13 \mathrm{ArH}$ aromatic protons, singlet at 8.56 acidic $\mathrm{NH}$ proton which exchanged in D2O, 13C-NMR $\delta 110.7(2 \mathrm{C})$, $112.9(\mathrm{CH}), 114.4(\mathrm{CH}), 120.8(2 \mathrm{CH}), 123.2(2 \mathrm{CH}), 128.1(2 \mathrm{CH}), 130.8(\mathrm{CH}), 131.2(\mathrm{CH}), 132.1(2 \mathrm{CH}), 132.8(2 \mathrm{CH})$, 134.3(C), 136.8(CH), 138.1(CH), 141.1(C), 168.4(C), 190.0(C) and Anal. Calc. for C22H15N3OCl2: C 64.86, H 3.68, N 10.31; found: C 64.80, H 3.63, N 10.33. MS: m/z 407[M+.], 354, 236[M+.-(Ph)2O], 260, 235, 145.

General Procedure for the preparation of the compounds 5

A mixture of $4(0.01 \mathrm{~mol})$ and ammonium acetate $(2.31 \mathrm{~g}, 0.03 \mathrm{~mol})$ was heated in an oil bath at $190 \mathrm{OC}$ for variable time. The mixture was poured onto water after cooling. The solid that separated after cool was filtered off, dried and then, crystallized from the proper solvents.

3,4-Bis(4-chlorophenyl)-4,5-dihydro-5-phenyl-imidazolo[4,5-c] pyrazole (5). Yield 78\%. m.p. 122-124. IR(KBr) v 3264, 3197(NH), 3050 (CHAr), 1630 (C=N). 1HNMR (DMSO): $\delta$ multiplet 5.3(s,1H, CHAr), $7.22-7.89$ assigned for $13 \mathrm{ArH}$ aromatic protons, singlet at 10.1 and 12.9 a acidic $2 \mathrm{NH}$ protons which exchanged in $\mathrm{D} 2 \mathrm{O}, 13 \mathrm{C}-\mathrm{NMR}$ $\delta 110.7(2 \mathrm{C}), 112.9(\mathrm{CH}), 114.4(\mathrm{CH}), 120.8(2 \mathrm{CH}), 123.2(2 \mathrm{CH}), 128.1(2 \mathrm{CH}), 130.8(\mathrm{CH}), 131.2(\mathrm{CH}), 132.1(2 \mathrm{CH})$, $132.8(2 \mathrm{CH}), 134.3(\mathrm{C}), 136.8(\mathrm{CH}), 138.1(\mathrm{CH}), 141.1(\mathrm{C}), 167.4(\mathrm{C}), 168.0(\mathrm{C})$ and Anal. Calc. for $\mathrm{C} 22 \mathrm{H} 16 \mathrm{~N} 4 \mathrm{Cl} 2 \mathrm{:} \mathrm{C}$ 65.02, H 3.94, N 13.79, Cl 17.24; found: C 65.01, H 3.94, N 13.78, Cl 17.23; MS:m/z 370.5[M+.-Cl], 295[M+.$\mathrm{PhCl}, 281$.

General Procedure for the preparation of the compounds 6 
An equimolar mixture of compounds $4(0.01 \mathrm{~mol})$ and hydrazine hydrate $(0.01 \mathrm{~mol})$ in $50 \mathrm{~mL}$ boiling ethanol. The reaction mixture was refluxed for $6 \mathrm{~h}$. The solid that separated after cool was filtered off, washed by petroleum ether (b.p 40-60oC), dried and then, crystallized from the proper solvents.

3,4-Di(4-chlorophenyl)-6-phenyl- 1,2,3,4-tetrahydropyrazolo[3,4-e]1,2,4-triazine (6). Yield 77\%. m.p. 122-124. $\mathrm{IR}(\mathrm{KBr}) \vee$ 3484, 3197(NH), 3058 (CHAr), 1602 (C=N). 1HNMR (DMSO): 8 3.93(s,1H, CHAr), 7.09 -7.98 (m, 13ArH aromatic protons), broad singlet at $6.7,8.55$ and 12.9 a acidic $3 \mathrm{NH}$ protons which exchanged in $\mathrm{D} 2 \mathrm{O}$, protons which exchanged in D2O, 13C-NMR $\delta 110.9(2 \mathrm{C}), 113.9(\mathrm{CH}), 115.4(\mathrm{CH}), 117.8(2 \mathrm{CH}), 120.2(2 \mathrm{CH}), 126.7(2 \mathrm{CH})$, 128.8(CH), 130.2(CH), 132.1(2CH), 132.9(2CH), 134.3(C), 136.8(CH), 138.1(CH), 141.1(C), 167.4(C), 168.0(C) and Anal. Calc. for C22H17N5Cl2: C 62.70, H 4.03, N 16.62, Cl 16.62; found: C 62.69, H 3.99, N 16.58, Cl 16.60; MS:m/z 421[M+.], 385[M+.-Cl], 281, 139.5, 111.5, and Anal. Calc. for C22H17N5Cl2: C 62.70, H 4.03, N 16.62, Cl 16.62; found: C 62.69, H 3.99, N 16.58, Cl 16.60; MS:m/z 421[M+.], 385[M+.-Cl], 281, 139.5, 111.5.

General Procedure for the preparation of the compounds 7

An equimolar mixture of compound $4(2.26-3.14 \mathrm{~g} ; 0.01 \mathrm{~mol})$ and urea $(0.01 \mathrm{~mol})$ in $50 \mathrm{~mL}$ boiling ethanol. The reaction mixture was refluxed for $4 \mathrm{~h}$. The solid that separated after cool was filtered off, washed by petroleum ether (b.p 40-60oC), dried and then, fraction crystallized from ethanol.

3,6-Di(4-chlorophenyl)-[1H] pyrazolo [1,2-a]1,3,5-triazine (7). Yield 26\%. m.p. 302-304. IR(KBr) v 3336, 3290(NH), 3050 (CHAr), 1628 (C=N). 1HNMR (DMSO): $\delta$ multiplet at $7.50-8.11$ assigned for 16ArH aromatic protons, singlet 13.2 acidic $\mathrm{NH}$ proton which exchanged in D2O, 13C-NMR $\delta 111.4(2 \mathrm{C}), 121.3(2 \mathrm{CH})$, $123.9(2 \mathrm{CH}), \quad 126.0(2 \mathrm{CH}), \quad 129.0(2 \mathrm{CH}), \quad 131.7(2 \mathrm{C}), \quad 132.0(2 \mathrm{C}), \quad 133.3(2 \mathrm{CH}), \quad 133.8(2 \mathrm{CH}), \quad 137.0(2 \mathrm{C})$, 137.5(2C),139.4(2CH), 142.1(2CH), 167.42C), 192.1(2C) and Anal. Calc. for C29H17N3O2Cl4: C 59.89, H 2.92, N 7.22, Cl 24.44; found: C 59.87, H 2.92, N 7.24, Cl 24.45. MS:m/z 584[M+.+2], 581[M+.], 263.5, 235, 193 [3amino -5(4- chlorophenyl) pyrazole] +.

General Procedure for the preparation of the compounds 8

A mixture of $4(0.01 \mathrm{~mol})$ and acetic anhydride $(9.4 \mathrm{~mL}, 0.1 \mathrm{~mol})$ and then refluxed on water bath for $2 \mathrm{~h}$. The excess acetic anhydride was removed by distillation and the separated product was filtered, dried and were recrystallized from mix toluene-ethanol.

5,6-Bis(4-chlorophenyl) pyrazolo[1,2-a]1,3,5-triazine (8a). Yield 74\%. m.p. 146-148. IR(KBr) 3050(CHAr), 2952(CHAli), 1613(C=N). 1HNMR (DMSO): $\delta 3.5(\mathrm{~s}, 3 \mathrm{H}, \mathrm{CH} 3), 7.22-7.75$ (m, 8H, ArH). 13C-NMR $\delta ~ 22.4(\mathrm{CH} 3)$, 109.6(CH), 121.7(CH), 129.7(2CH), 132.5(CH), 133.2(CH), 133.6(CH), $134.6(\mathrm{CH}), 138.6(2 \mathrm{C}), 140.2(\mathrm{C}), 141.5(\mathrm{C})$, 143.4(C), 144.1(C), 152.6(C), 190.2(C) and Anal. Calc. for C17H11N3OCl2: C 59.47, H 3.20, N 12.24, Cl 20.40; found: C 59.46, H 3.19, N 12.22, Cl 20.39. MS: m/z 343 [M+], 328, 285, 121[M+-(2PhCl)],

5,6-Di(4-chlorophenyl) pyrazolo[1,2-a] 1,3,5-triazine(8b). Yield 70\%. m.p. 136-138. IR(KBr) 3061(CHAr), 2922(CHAli),1630 (C=N), 1HNMR (DMSO): $\delta 4.24(\mathrm{~s}, 3 \mathrm{H}, \mathrm{CH} 3), 6.96-7.55(\mathrm{~m}, 6 \mathrm{H}, \mathrm{ArH}) .13 \mathrm{C}-\mathrm{NMR} \delta 23.2(\mathrm{CH} 3)$, 129.7(CH),132.5 (CH), 133.6(CH), 134.6(CH), 138.6(CH), 138.9(CH), 141.5(C), 143.4(C), 144.1(C), 189.6(2C), 192.2(C), and Anal. Calc. for C13H9N3O3: C 61.17, H 3.52, N 16.47; found: C 61.15, H 3.50, N 16.43. MS: m/z $255[\mathrm{M}+], 240,197,188$.

5,6-Di-(4-chlorophenyl)-pyrazolo[1,2-c]1,3,5-thiadiazine (9). Yield 34\%. m.p.188-190. IR(KBr) 3435(NH), 3045(CHAr), 1660 (C=O).1HNMR (DMSO): $\delta 1.52(\mathrm{~s}, 3 \mathrm{H}, \mathrm{CH} 3), 7.26-7.59(\mathrm{~m}, 8 \mathrm{H}, \mathrm{ArH})$, singlet 14.07 acidic NH proton which exchanged in D2O, 13C-NMR $\delta 21.5(\mathrm{CH} 3), 108.1(\mathrm{CH}), 120.5(\mathrm{CH}), 125.8(\mathrm{CH}), 128.6(\mathrm{CH})$, 
130.7(CH), 131.0(CH), 132.6(CH), 135.6(C), 138.3(C), 137.6(CH), $140.2(\mathrm{C}), 141.5(\mathrm{C}), 142.4(\mathrm{C}), 146.1(\mathrm{C})$, 161.2(C), 190.7(C) and Anal. Calc. for $\mathrm{C} 17 \mathrm{H} 12 \mathrm{~N} 3 \mathrm{O} 2 \mathrm{Cl}$ : C 62.67, H 3.68, N 12.90, Cl 10.90; found: C 62.63, H 3.67, $\mathrm{N}$ 12.91, Cl 10.92. MS: m/z 326[M+], 268.5 [M+-MeN=C=O], 213 [M+-PhCl.].

\section{Reference}

1. K. Nishiyama, G. W. Griffin, K. Ishikawa, and D. M.Gibson, J. Org. Chem. 1982, 47, 2342. b) L. Zheng, X. Jun, N. Pengxian, L. Chenhui, and Y. Jingya, Tetrahedron, 2012, 68, 8880

2. G. Daidone, B. Maggio, S. Plescia, D. Raff, C. Musiu, C. Milia, G. Perra, and M. E.Marongiu, Eur. J. Med.chem., 1998, 33,375.

3. N. Singh, N. K. Sangwan, and K. S. Dhindsa, Pest manage. Sci., 2000, 56, 284.

4. G. Daidone, D. Raffa, F. Plescia, B. Maggio, and A. Roccaro, Arkivoc 2002, xi, 227.

5. O. Migliara, S. Plescia, P. Diana, V. Distefano, L. Camarda, and O. R. Dall, Arkivoc 2004, v, 44.

6. Bouabdallah, L.A. Barek, A. Zayed, A.Ramadani, I. Zidane, and A. Melhaoui, Natural product research, 2006, 20(11), 1024.

7. S. Nagaaki, J. Makoto, I. Shiho, N. Keita, T. Hiroyasu, A. Makoto, O. Osamu, I. Hisashi, G. Akira, I. Akane, K. Akio, and F. Takehiro, Bioorganic \& Medicinal Chemistry Letters 2009, 19, 1670.

8. P. Dariusz, M. B. Andrzej, E. L. Agnieszk, J. S. Bohdan, and K. Jerzy, Acta Poloniae Pharmaceutica ñ Drug Research, 2007, 64(6) 535.

9. Ø. Justyna, O. Dorota, Z. Zofia, A. Ewa, and Z. Lucjusz, Acta Poloniae Pharmaceutica ñ Drug Research, 2008, 65, 229.

10. C. S. Prabodh, V. S. Sunil, J. Sandeep, S. Dalbir, and S. Bhojraj, Acta Poloniae Pharmaceutica ñ Drug Research, 2009, 66(1), 101.

11. M. Marcin, Z. Michal, T. Magdalena, and R. Stanislaw, Acta Poloniae Pharmaceutica ñ Drug Research, 2008, 65(5): 543.

12. M. C. Marcin, Z. Michal, A.R. Stanise, Acta Poloniae Pharmaceutica ñ Drug Research, 2008, 65(2), 241.

13. M. B. Alvarez, M. Palmeri, D. Davis, and J. S. Fritz, Talanta. 1987, 34, 473.

14. D. K. Johnson, T. B. Murphy, and W. H. Goodwin, Inorg. Chim. Acta 1982, 67, 159.

15. K. Shreenivasan, S. Perrier, S. Kochi, J. Mol. Catal. 1986, 36, 297.

16. M. H. Ali, S. E. Livingston: Coord. Chem. Rev. 1974, 13, 126.

17. M. Jain, S. Nehra, P. C.Trivedi, R. V. Singh, Metal-based drugs 2002, 9, 53.

18. M. Jain, R.V. Singh, Ind. J. Chem. Sci. 2003, 1, 17.

19. R.M. Patil, Acta Poloniae Pharmaceutica ñ Drug Research, 2007, 64(4), 345.

20. R.M. Patil, and N. V. Thakkar, Met. Org. Chem. 2000, 30, 1159. 
21. S. A. Rizk, M. A. EL-Hashash, and M. M. Aburzeza, Egypt. J. Chem. 2011, 54(3), 299.

22. M. A. El-Hashash, S. A. Rizk, J Heterocyclic Chem 2017, 54, 1776.

23. S. A. Rizk, M.A. El-Hashash, K. K. Mostafa, Egypt, J. Chem. 2008, 51(5), 116.

24. S. A. Rizk, Amira A. El-Sayed, and Marwa M. Mounier, J. Heterocyclic Chem., 2017, 54, 3358.

25. M.E. Azab, S.A. Rizk, A. E. Amr, Molecules 2015, 20, 18201-18218.

26. D. N. Dhar, The Chemistry of chalcones and related compounds, Wiley-Interscience, New York, 1981, 228

27. J. R. Dimmock, D. W. Elias, M. A. Beazely, and N. M. Kandepu, Curr. Med. Chem. 1999, 6, 1125-1150.

28. G.D .Carlo, N. Mascolo, A.A. Izzo, and F. Capasso, Life Sci., 1999, 65(4), 337-353.

29. S. V. Kostanecki, and Tambor, J. Chem Ber., 1899, 32, 1921

30. R.K. Saini, A.S. Choudhary, Y.C. Joshi, and P. Joshi, E-J. Chem., 2006, 2(4), 224-227

31. H. Takayanagri, Y. Kitano, T. Yano, H. Umeki, and H. Hara, J. Can. Pat. Appl. 1995, 93(50),128. 